\title{
Psychopathological symptoms of patients with heroin addiction entering opioid agonist or therapeutic community treatment
}

Pier Paolo Pani ${ }^{1}$, Emanuela Trogu ${ }^{2}$, Federica Vigna-Taglianti ${ }^{3,4}$, Federica Mathis $^{3}$, Roberto Diecidue ${ }^{3}$, Ursula Kirchmayer $^{5}$, Laura Amato ${ }^{5}$, Marina Davoli ${ }^{5}$, Joli Ghibaudi ${ }^{6}$, Antonella Camposeragna ${ }^{6}$, Alessio Saponaro ${ }^{7}$, Fabrizio Faggiano ${ }^{8}$, Angelo Giovanni Icro Maremmani ${ }^{9,10}$ and Icro Maremmani ${ }^{9,10,11^{*}}$

\begin{abstract}
Background: The relationship between substance use disorders and psychiatric pathology is still an open question. The main aim of the present study was to verify whether the five psychopathological dimensions identified through the SCL-90 tool in a previous study carried out on patients with heroin addiction entering an outpatient opioid agonist treatment (OAT) were also observable in those entering a residential treatment community (TC). Further aims were to look at differences in the psychopathological profiles of patients entering a TC versus an OAT treatment and at the correlation between gender and the observed psychopathology.
\end{abstract}

Methods: A confirmatory factor analysis was performed on the results of SCL-90 filled by 1,195 patients with heroin dependence entering TC treatment. It replicates the extraction method previously used on 1,055 OAT patients with heroin addiction by using a principal component factor analysis (PCA). The association between the kind of treatment received (TC or OAT), gender, and the psychopathological dimensions was assessed through logistic regression and general linear model (GLM) analysis.

Results: The PCA carried out on the SCL-90 results of patients entering a TC yielded a five-factor solution, confirming the same dimensions observed in patients entering an OAT: 'worthlessness and being trapped', 'somatization', 'sensitivity-psychoticism', 'panic anxiety', and 'violence-suicide'. The logistic regression analysis showed a statistically significant association between 'somatization' and 'violence-suicide' severity score and OAT. GLM analysis showed that psychopathological factorial scores for 'worthlessness-being trapped', 'somatic symptoms', and 'panic anxiety' dimensions were more severe in OAT vs TC male patients and in TC vs OAT female ones. Violence suicide' followed the same severity pattern for males, but did not differ in TC vs OAT females, while 'sensitivity-psychoticism' did not differ in OAT vs TC patients. The five dimensions did not differ in OAT males vs females.

Conclusions: Our research appears to confirm the existence of a specific aggregation of psychological/psychiatric features within the category of individuals with heroin addiction. It also shows a correlation between the dominant psychopathological subgroup and the assignment to TC versus OAT. Further research is needed to clarify the differences between the five psychopathological subgroups and their determinants.

Keywords: Psychopathological symptoms, SCL-90, Residential treatment community, Opioid agonist treatment, Gender differences

\footnotetext{
* Correspondence: maremman@med.unipi.it

${ }^{9}$ Department of Neurosciences, Vincent P. Dole Dual Diagnosis Unit, Santa

Chiara University Hospital, University of Pisa, Pisa, Italy

${ }^{10}$ Association for the Application of Neuroscientific Knowledge to Social

Aims (AU-CNS), Pietrasanta, Lucca, Italy

Full list of author information is available at the end of the article
}

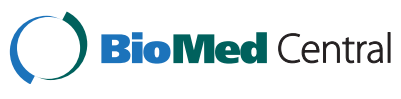

(c) 2014 Pani et al.; licensee BioMed Central Ltd. This is an Open Access article distributed under the terms of the Creative Commons Attribution License (http://creativecommons.org/licenses/by/4.0), which permits unrestricted use, distribution, and reproduction in any medium, provided the original work is properly credited. The Creative Commons Public Domain Dedication waiver (http://creativecommons.org/publicdomain/zero/1.0/) applies to the data made available in this article, unless otherwise stated. 


\section{Background}

The relationship between substance use and other psychiatric disorders is still an open question. According to current nosographic approaches-especially the one followed by the Diagnostic and Statistical Manual of Mental Disorders (DSM) system, even in its recent fifth version [1] - substance use disorders are defined by the core symptoms of addiction, such as continuation of use despite consequences, reduction of other interests and activities, and craving. Other relevant psychopathological symptoms present in the clinical picture of persons with addictive behaviours are included in separate disorders pertaining to the domain of psychiatric 'comorbidity'. Several findings challenge this 'dividing' approach to unitary clinical presentations: besides the high degree of association between core symptoms of addiction and other psychiatric symptoms [2-4], various neurobiological and clinical considerations highlight the strong link between addiction as such and other forms of psychopathology [5-10]. Accordingly, a revision of the current nosology is needed, moving to approaches based on dimensions of observable behaviour and neurobiological measures [11]. On these bases, an integrated, unified approach, which aims to explain the pathophysiology and phenomenology of addiction, including psychological/ psychiatric precursors, acute substance effects, addictive processes, and psychiatric consequences, has been previously proposed $[12,13]$. Actually, a clinical diagnosis of a psychiatric disorder in the presence of substance addiction is a difficult task. The short- and long-term effects of substances, their withdrawal, and the consequences of addictive processes result in symptoms that cannot be clearly distinguished from those produced by independent psychiatric disorders or psychological conditions preceding substance use. The use of structured and semi-structured interviews has certainly improved the reliability of comorbid psychiatric diagnoses. However, even with the support of these interviews, the reliability of diagnoses remains weak [14-18].

Given this background, and the consequent uncertainty in the correct classification of symptomatology as being intrinsic to the addictive disorder or as due to comorbidity, a low level of inference has been considered in approaching the psychopathology of addiction, while focusing primarily on the symptoms expressed by patients rather than starting from a pre-established syndromic level such as that of the DSM [19-22].

Following this approach, some years ago, our research group applied an exploratory principal component factor analysis (PCA) to symptoms shown by a sample of patients entering an outpatient opioid agonist treatment (OAT) in the city of Pisa [21]. The analysis yielded a three-factor solution identifying 1) a 'depressive-anxious' dimension (illness awareness, anxiety state, depressed mood, sleep and eating disturbances), 2) a 'psychomotor excitement' dimension (hypomanic/manic or mixed state, aggressiveness and violence, suicidality), 3) and a 'psychotic state' dimension, including memory deficits, altered consciousness, delusions, and hallucinations. Adopting a similar approach, Zack et al. applied a PCA to the 90 items listed in the SCL-90 questionnaire administered to a population of 740 outpatients with coexisting substance use (especially alcohol) and psychiatric disorders. This analysis yielded three inter-correlated factors that, taken together, accounted for $38 \%$ of the variance found in ratings from the entire sample: the first factor was characterized by anxious and depressive symptoms and identified as 'general emotional distress'; the second factor reflected a combination of bodily concerns and phobic avoidance and was labelled 'panic-related symptoms', and the third factor contained elements of hostile thought and behaviour as well as suspicious beliefs and was identified as 'hostility and suspiciousness'. In any case, a single higherorder factor was identified that explained $60 \%$ of the variance in factor scores. This study also tested the factor structure variations measured by the SCL-90 across gender-a subject on which inconsistencies had been reported in previous studies-so demonstrating a structural similarity between the factors as they appear separately in each gender [20].

In a further investigation carried out by our group, the SCL-90 checklist was used to investigate the psychopathological dimensions of 1,055 patients with heroin addiction who had been admitted to public addiction facilities in Italy and were beginning an OAT. By applying an exploratory PCA to the 90 items in SCL-90, a five-factor solution was identified: the first factor reflected a depressive 'worthlessness and being trapped' dimension, the second factor picked out a 'somatization' dimension, the third identified a 'sensitivity-psychoticism' dimension, the fourth a 'panic anxiety' dimension, and the fifth a 'violence-suicide' dimension [22]. Overall, the five factors accounted for $37.8 \%$ of the variance found between the items.

The main aim of the present study was to verify whether the five psychopathological dimensions identified in the previous study carried out with patients entering an OAT were also observable in subjects with heroin addiction entering a treatment community (TC). Further aims were to look at differences in the psychopathological profile of patients entering a TC versus an OAT treatment and to look at the correlation between gender and the psychopathology expressed through the SCL-90 by the enrolled patients.

Our expectations were that psychopathological subtypes previously observed in opioid dependents would be confirmed in a different sample of opioid dependents, that the severity of patients' psychopathology would be associated with the treatment modality chosen, and that 
the psychopathology expressed would be more severe in the female population.

\section{Methods \\ Setting}

Patients included in the present study come from two datasets: the first is the Pisa addiction dataset, a database that includes anonymous individual information on patients with heroin addiction receiving OAT at the Italian Addiction Services during the years 1995-2010, information originally collected for clinical or other research purposes. The second is the Evaluation of Therapeutic Community Treatments and Outcomes (VOECT) dataset, which includes individual information on patients with heroin addiction admitted to TC treatment in eight Italian regions in 2008-2009 [23].

\section{Sample}

The OAT sample consisted of 1,055 subjects, with diagnosis of heroin dependence according to DSM-IV criteria; they were evaluated at the time they entered OAT at Italian facilities. The mean age of this sample was $30.6 \pm 6.6$ years, $83.9 \%$ of the subjects were male, $83.1 \%$ were single, educational level was high (studies lasting over 8 years) in $10.1 \%$ of the sample, $56.6 \%$ of subjects were unemployed, and $22.9 \%$ were at their first treatment. Heroin history length was $7.3 \pm 6.0$ years on average.

Patients in the TC cohort $(n=1,195)$ received the diagnosis of heroin dependence according to clinical judgement; they were evaluated at the time they entered the TC. The mean age of this sample was $33.8 \pm 7.7$ years; $81.4 \%$ of the subjects were male, $90.2 \%$ were single, educational level was high (studies lasting more then 8 years) in $9.3 \%$ of the sample, $72.4 \%$ of the subjects were unemployed, and $3.2 \%$ were at their first treatment. Heroin history length was $12.2 \pm 8.1$ years on average.

Considered together, the two samples gave a heterogeneous cohort of 2,250 subjects with a diagnosis of heroin addiction. For the full sample, the mean age was $32.3 \pm$ 7.4 years (range: $15-62$ ). Of the subjects, 1,857 (82.5\%) were male, $2,032(90.3 \%)$ had a low educational level (studies lasting 8 years or less), 1,960 (87.1\%) were single, $1,516(67.4 \%)$ were unemployed, and 108 (4.8\%) were unable to work due to health impairment. The mean duration of addiction was 9.4 \pm 7.4 years ( $\min 0.8$, $\max 34.8)$. A total of $774(34.4 \%)$ had an addiction history lasting less than 5 years, 600 (26.7\%) lasting between 5 and 10 years, 358 (15.9\%) between 10 and 15 years, $292(13.0 \%)$ between 15 and 20 years, and 225 (10.0\%) over 20 years. All these patients were of Italian nationality and were included only once in the sample. In all, $270(12.0 \%)$ were beginning treatment for heroin addiction for the first time.

\section{Instruments}

After its development by Derogatis and colleagues [24], the SCL-90 now includes 90 items, each rated on a 5-point scale of distress. These items can be clustered in nine dimensions: somatization, obsession-compulsion, interpersonal sensitivity, depression, anxiety, anger-hostility, phobic anxiety, paranoid ideation, and psychoticism.

Four global scores can be calculated: 1) Total SCL-90 score (sum of all items); 2) General Symptomatic Index (GSI), the mean score of all recorded items; 3) Positive Symptoms Total (PST), the number of items rated positively; and 4) Positive Symptom Distress Index (PSDI), which is calculated by dividing the sum of all items by the PST score.

Information on other demographic and clinical characteristics of the patients included in the study was collected from clinical records or research questionnaires for the Pisa dataset and from a research questionnaire for the VOECT dataset.

\section{Data analyses}

The two groups of patients (entering OAT or TC services) were compared for socio-demographic and clinical characteristics by means of the chi-square test for categorical variables and of Student's $t$ test for continuous variables. A confirmatory factor analysis was then performed on the SCL-90 results of the 1,195 TC patients, replicating the same extraction method previously used on the 1,055 OAT patients [22]. Put simply, the single factors were extracted by using a PCA (type 2) and then rotating this orthogonally to achieve a simple structure. To limit the number of factors, the criterion used was an eigenvalue $>1.5$. Items loading with absolute values $>0.40$ were used to identify the factors. In order to make factor scores comparable, they were standardized into $z$ scores. All the subjects were then assigned to a different subtype on the basis of the highest factor score achieved (dominant SCL-90 factor). This procedure gives the opportunity to classify subjects on the basis of the highest symptomatological cluster. At this point, the correlations between the factors extracted in the two populations under study were estimated through Pearson correlation. Lastly, we looked at the inter-rated reliability (Cohen's kappa) of the factorial analyses, applying the two factor solutions to the TC patients. We considered a Kappa value higher than 0.60 as indicating that the two factor solutions are very similar [25]. Given this similarity, the factor solution identified in the OAT sample was used to compare patients receiving OAT with those receiving therapy in a TC.

The association between dominant psychopathological group and the kind of treatment received (OAT and TC) was assessed through a logistic regression analysis applied to the whole sample of 2,250 subjects resulting from merging the two datasets. In order to take into account 
differences between the samples, socio-demographic and clinical variables statistically different between TC and OAT patients in the basic analyses were included into the regression model: age, gender, heroin history length, previous treatments, working condition, and welfare benefits.

Finally, the general linear model (GLM) was used to compare psychopathological factorial scores, according to the 'Group (OAT vs TC) + Gender + Group $\times$ Gender' design, between the two samples of patients, adjusting for age and heroin history length. All analyses were carried out using SPSS v. 4.0 (SPSS, Chicago, IL, USA). Statistical significance was set at the $p=0.05$ level.

\section{Results}

\section{Comparison between OAT and TC patients}

The TC patients were older (33.87 \pm 7.7 years) than the OAT ones (30.56 \pm 6.6 years). This difference was statistically significant $(T=-10.45 ; p=0.000)$. Of the sample, $90.2 \%$ of the TC patients and $83.1 \%$ of the OAT patients were single (chi-square $=23.06 ; p=0.000) ; 72.4 \%$ and $56.6 \%$ were unemployed (chi-square $=35.35 ; p=0.000$ ); $6.6 \%$ and $2.7 \%$, respectively, received welfare benefits (chisquare $=18.23 ; p=0.000$ ); and $3.2 \%$ and $22.9 \%$, respectively, were at their first treatment (chi-square $=196.20$; $p=0.000)$. Heroin history length was longer (12.22 \pm 8.1 years) in the TC patients than in the OAT ones (7.28 $\pm 6.0 ; T=-14.28 ; p=0.000)$.

Males were $81.4 \%$ among the TC patients and $83.9 \%$ among the OAT patients. No differences were observed as regards to gender: the female/male ratio was 1:4.3 for patients in the TC sample and 1:5.2 in the OAT patients ( $p=0.131)$. Educational level was high (studies lasting over 8 years) in $9.3 \%$ of the TC patients and in $10.1 \%$ of the OAT ones $(p=0.558)$.

\section{Confirmatory factor analysis}

The PCA applied to the TC sample confirmed a fivefactor solution. Altogether, 76 items with a loading $>0.40$ were retained. 'Worthlessness' and 'being trapped' were the two leading items in the first depressive dimension; this accounted for $33.3 \%$ of the variance. The 'somatization' dimension was the second factor, accounting for $3.7 \%$ of the variance. The third factor confirmed the 'sensitivitypsychoticism' dimension; this accounted for 3.3\% of the total variance. Panic symptoms loaded on the fourth factor, the 'panic-anxiety' dimension, accounting for $2.3 \%$ of the total variance. The last, fifth factor, confirmed a 'violence suicide' dimension, which accounted for $2.0 \%$ of the total variance. Overall, these five factors accounted for $44.6 \%$ of the variance between the recorded items.

On the basis of the highest $z$ scores obtained on the five SCL-90 factors (dominant SCL-90 factor), subjects whose dominant factor was 'worthlessness and being trapped' included 199 subjects (16.7\%); the group with 'somatization' as dominant factor comprised 207 subjects (17.3\%), the group with 'sensitivity-psychoticism' numbered 252 subjects (21.1\%), the group with 'panic-anxiety' had 350 subjects (29.3\%), and the group whose dominant factor was 'violence-suicide' was made up of a cluster of 187 subjects (15.5\%).

Correlating factorial scores derived from the exploratory and the confirmatory factor analyses, the first factors correlated with a Pearson's $r=0.80$, the second with $r=0.69$, the third with $r=0.79$, the fourth with $r=0.72$, and the fifth with $r=0.61$. All these correlations were statistically significant $(p<0.001)$.

After assigning TC patients to five mutually exclusive groups using exploratory and confirmatory analysis, Cohen's kappa was 0.60 .

As regards the results of the logistic regression analysis carried out on the whole sample obtained by merging the two groups of patients admitted to TC and OAT (Table 1), among the five extracted factors, both the 'somatic symptoms' and the 'violence-suicide' dominant psychopathological group membership were associated at a statistically significant level with the OAT group membership. Among potential confounding factors, both the female gender and the heroin history length were significantly associated with the TC group, whereas being at first treatment and having a job were associated with the OAT group. Age and presence of welfare benefits did not enter the regression equation.

\section{Gender and psychopathology}

Table 2 shows the differences of SCL-90 indexes between males and females in OAT and TC. Multivariate analysis showed significant differences between the two groups $(F=8.66 ; d f=4 ; p=0.000)$, the two genders $(F=7.31$; $d f=4 ; p=0.000)$, and a group by gender interaction $(F=8.79 ; d f=4 ; p=0.000)$. In particular, total SCL-90 did not differ between the groups; group-gender interaction was statistically significant, with male patients in the TC group showing lower scores and TC females higher ones than the OAT group pairs. The same pattern was observed for GSI. PST was higher in patients in the OAT group than in the TC patients. The same pattern was observed with PSDI. For all indexes, the lowest scores were found among TC males and the highest among TC females. Significant correlations were maintained when the age and duration of dependence were included as covariates $(F=2.41 ; p=001)$. As the relationship between psychopathological factorial scores and marital status $(F=1.09$; $p=0.35)$, employment $(F=1.19 ; p=0.31)$, welfare benefits $(F=0.08 ; p=0.98)$, and previous treatment $(F=1.27$; $p=0.27$ ) did not reach statistical significance (data not shown), these variables were not included in the model.

Table 3 shows differences between males and females in OAT and TC as regards the five SCL-90 dominant 
Table 1 Logistic regression carried out in 2,250 heroin-addicted patients at treatment entry

\begin{tabular}{|c|c|c|c|c|c|c|}
\hline & STEP & $B$ & Odds ratio & Min & Max & $P$ \\
\hline \multicolumn{7}{|l|}{ Variables in equation } \\
\hline Being at first treatment & 1 & -2.42 & 0.08 & 0.05 & 0.15 & 0.000 \\
\hline Heroin history length & 2 & 0.008 & 1.01 & 1.006 & 1.009 & 0.000 \\
\hline Working & 3 & -0.55 & 0.57 & 0.44 & 0.74 & 0.000 \\
\hline SCL-90 dominant groups & 4 & & & & & 0.000 \\
\hline SCL-90 dominant group (somatic symptom) ${ }^{a}$ & & -7.48 & 0.47 & 0.32 & 0.69 & 0.000 \\
\hline SCL-90 dominant group (sensitivity-psychoticism) ${ }^{a}$ & & -0.19 & 0.82 & 0.54 & 1.23 & 0.344 \\
\hline SCL-90 dominant group (panic anxiety) ${ }^{a}$ & & 0.16 & 1.01 & 0.68 & 1.51 & 0.938 \\
\hline SCL-90 dominant group (violence-suicide) ${ }^{a}$ & & -0.41 & 0.66 & 0.43 & 0.99 & 0.049 \\
\hline Female gender & 5 & 0.35 & 1.42 & 1.03 & 1.94 & 0.028 \\
\hline \multicolumn{7}{|l|}{ Variables not in equation } \\
\hline \multicolumn{7}{|l|}{ Presence of welfare benefits } \\
\hline \multicolumn{7}{|l|}{ Age } \\
\hline Statistic: chi-square 321.70, df 8, $p<001$ & & & & & & \\
\hline
\end{tabular}

It includes SCL-90 factors and other demographic and clinical variables as determinants, and treatment group (TC versus AOT) as a dependent variable.

${ }^{a}$ Considering dominant 'worthlessness-being trapped' as reference group.

group membership. Multivariate analysis showed significant differences between the two groups $(F=16.65 ; d f=5$; $p=0.000)$, the two genders $(F=76.39 ; d f=5 ; p=0.000)$ and group-gender interaction $(F=10.09 ; d f=45$; $p=0.000)$. In particular, the 'worthlessness-being trapped' dimension was more severe in patients in the OAT group than in TC group patients, and in females within the TC group than in males. The same pattern was observed regarding 'somatic symptoms', 'panic anxiety', and 'violence-suicide'. 'Sensitivity-psychoticism' did not differ between the two groups, and a similar pattern was found between the genders: males of the TC group scored lowest, and females highest. Again, significant correlations were maintained when age and duration of dependence were included as covariates $(F=2.87 ; p=0.000)$, while the relationship between psychopathological factorial scores and marital status $(F=1.04 ; p=0.39)$, employment $(F=1.41 ; p=0.21)$, welfare benefits $(F=0.63 ; p=0.67)$, and previous treatment $(F=0.38 ; p=0.86)$ was not statistically significant; therefore, these variables were not included in the model.

\section{Discussion}

The primary aim of the present study was to verify whether the five psychopathological dimensions identified through the SCL-90 in a previous study carried out on patients entering an outpatient OAT were also observable in patients with heroin addiction entering a residential

Table 2 Differences between OAT and TC patients in SCL-90 indexes by gender

\begin{tabular}{|c|c|c|c|c|c|}
\hline & \multicolumn{2}{|c|}{ OAT patients } & \multicolumn{2}{|l|}{ TC patients } & \multirow[t]{2}{*}{ Statistics } \\
\hline & Males & Females & Males & Females & \\
\hline \multirow[t]{3}{*}{ Total SCL-90 } & $89.67 \pm 54.8$ & $89.37 \pm 54.5$ & $73.95 \pm 55.3$ & $107.02 \pm 58.0$ & $\mathrm{Gr}: F=0.09 ; p=0.759$ \\
\hline & & & & & Ge: $F=26.98 ; p=0.000$ \\
\hline & & & & & $\mathrm{Gr} \times \mathrm{Ge}: F=27.96 ; p=0.000$ \\
\hline \multirow[t]{3}{*}{ General Symptomatic Index } & $0.99 \pm 0.6$ & $0.99 \pm 0.6$ & $0.82 \pm 0.6$ & $1.18 \pm 0.6$ & $\mathrm{Gr}: F=0.06 ; p=0.799$ \\
\hline & & & & & Ge: $F=26.48 ; p=0.000$ \\
\hline & & & & & $\mathrm{Gr} \times \mathrm{Ge}: F=28.35 ; p=0.000$ \\
\hline \multirow[t]{3}{*}{ Positive symptoms total } & $48.09 \pm 18.1$ & $47.64 \pm 18.3$ & $39.92 \pm 19.6$ & $50.75 \pm 19.0$ & $\mathrm{Gr}: F=5.52 ; p=0.019$ \\
\hline & & & & & Ge: $F=23.12 ; p=0.000$ \\
\hline & & & & & $\mathrm{Gr} \times \mathrm{Ge}: F=27.36 ; p=0.000$ \\
\hline \multirow[t]{3}{*}{ Positive symptom distress index } & $1.77 \pm 0.7$ & $1.75 \pm 0.5$ & $1.69 \pm 0.5$ & $1.99 \pm 0.5$ & $\mathrm{Gr}: F=4.68 ; p=0.031$ \\
\hline & & & & & Ge: $F=15.71 ; p=0.000$ \\
\hline & & & & & $\mathrm{Gr} \times \mathrm{Ge}: F=19.32 ; p=0.000$ \\
\hline
\end{tabular}


Table 3 Differences between OAT and TC patients in SCL-90 indexes by gender

\begin{tabular}{|c|c|c|c|c|c|}
\hline & \multicolumn{2}{|c|}{ OAT patients } & \multicolumn{2}{|c|}{ TC patients } & \multirow[t]{2}{*}{ Statistics } \\
\hline & Males & Females & Males & Females & \\
\hline \multirow[t]{3}{*}{ Worthlessness-being trapped } & $1.22 \pm 0.7$ & $1.20 \pm 0.7$ & $1.04 \pm 0.7$ & $1.54 \pm 0.8$ & $\mathrm{Gr}: F=3.76 ; p=0.052$ \\
\hline & & & & & Ge: $F=28.62 ; p=0.000$ \\
\hline & & & & & $\mathrm{Gr} \times \mathrm{Ge}: F=33.83 ; p=0.000$ \\
\hline \multirow[t]{3}{*}{ Somatic symptoms } & $1.28 \pm 0.7$ & $1.27 \pm 0.8$ & $0.93 \pm 0.7$ & $1.35 \pm 0.7$ & Gr: $F=10.12 ; p=0.001$ \\
\hline & & & & & Ge: $F=22.80 ; p=0.000$ \\
\hline & & & & & $\mathrm{Gr} \times \mathrm{Ge}: F=25.14 ; p=0.000$ \\
\hline \multirow[t]{3}{*}{ Sensitivity-psychoticism } & $0.82 \pm 0.6$ & $0.82 \pm 0.6$ & $0.72 \pm 0.6$ & $1.01 \pm 0.7$ & $G r: F=1.50 ; p=0.221$ \\
\hline & & & & & Ge: $F=14.79 ; p=0.000$ \\
\hline & & & & & $\mathrm{Gr} \times \mathrm{Ge}: F=15.77 ; p=0.000$ \\
\hline \multirow[t]{3}{*}{ Panic-anxiety } & $0.45 \pm 0.5$ & $0.44 \pm 0.5$ & $0.37 \pm 0.5$ & $0.67 \pm 0.6$ & $\mathrm{Gr}: F=4.44 ; p=0.035$ \\
\hline & & & & & Ge: $F=18.30 ; p=0.000$ \\
\hline & & & & & $\mathrm{Gr} \times \mathrm{Ge}: F=20.70 ; p=0.000$ \\
\hline \multirow[t]{3}{*}{ Violence-suicide } & $0.94 \pm 0.7$ & $1.01 \pm 0.7$ & $0.74 \pm 0.6$ & $1.00 \pm 0.7$ & $G r: F=6.60 ; p=0.010$ \\
\hline & & & & & Ge: $F=16.19 ; p=0.000$ \\
\hline & & & & & $\mathrm{Gr} \times \mathrm{Ge}: F=6.07 ; p=0.014$ \\
\hline
\end{tabular}

Gr group, Ge gender.

TC. Additional aims were to look at differences in the psychopathological profile of subjects entering a TC versus an OAT treatment and to look at the correlation between gender and the observed psychopathology.

The factorial analysis applied to the SCL-90 scores of subjects with opioid addiction entering a residential TC yielded the same five-factor solution obtained for subjects with opioid addiction entering an OAT. These five dimensions have been previously discussed in the light of the available literature on the physiopathology and psychopathology of addiction (see Maremmani et al. [22]). Expressed concisely, the first dimension ('worthlessness and being trapped') may be explained by the close link between mood disorders and addiction, in terms of neurobiological background, psychological and psychopathological risk factors, and the epidemiology of the two conditions [8,26-32]. The second dimension ('somatization') may be accounted for on the grounds of opioid withdrawal symptomatology, which may be correlated with the request for treatment. Withdrawal status may also be involved in the fourth factor ('panic-anxiety'), due to the overlap between anxiety and withdrawal symptomatology, and shared features in terms of neurobiology and physiopathology [33-35]. The third dimension ('sensitivity-psychoticism') may be understood in the light of self-treatment theory, as the consequence of the antipsychotic action of opioids [36-43] or as a consequence of a concomitant abuse of stimulants or cannabis [44-52]. The last dimension ('violence-suicide') is marked by impulsiveness, which is a major feature of addictive behaviour, as can be explained by the common neurobiological background, involving the limbic system and prefrontal cortex, and risk factors, such as antisociality and drugrelated disinhibition [53-61].

The results of the above confirmatory factor analysis need to be discussed in the light of the heterogeneity of the two samples considered. Actually, the two groups (subjects with heroin addiction entering OAT and those entering residential TC) differ in important factors related to socio-demographic and clinical conditions, treatment setting, and programme characteristics. As regards sociodemographic and clinical characteristics, patients entering OAT or TC did not differ in gender and educational level, but they did differ in age, marital status, employment, welfare benefits, previous treatment, and heroin history length. Patients in the TC group were significantly older, showed a higher percentage of singles, unemployed, and those receiving welfare benefits. They had a statistically significant longer history of heroin use and a greater number of previous treatments than those in the OAT group. As regards settings and the organization of treatment programmes, too, the choices regarding the two groups were clearly divergent: in the first case, there is a highly standardized programme, such as methadone or buprenorphine maintenance, distinguished by its scientifically proven efficacy, governed by guidelines and clear operational procedures [62-64]; in the second, a less standardized and more heterogeneous residential programme, subject to changes and adaptations undertaken to satisfy the needs of a special population (women, adolescents, people affected by psychiatric comorbidity), and financial limitations [65-68]. 
The TC patients included in our study were drawn from $121 \mathrm{TC}$ setups in eight Italian regions [23]. These communities differ in the variety of the services offered (pharmacological, including opioid agonist treatment, psychological, psychiatric, educational, social, rehabilitative, and work training), for the target population (males, mother-and-child, with a double diagnosis, with polydependence), and in the length of the treatment provided (ranging from a few months to a few years) [23].

In spite of such a high level of heterogeneity in treatment settings and programmes and of the existence of such relevant and statistically significant differences in socio-demographic and clinical characteristics, the SCL90 patterns obtained through PCA analysis are the same for the two groups, OAT and TCs. According to these results, the five psychological/psychiatric dimensions ('worthlessness-being trapped', 'somatic symptoms', 'sensitivity-psychoticism','panic-anxiety', 'violence-suicide') might be considered as characteristics of the psychopathology of subjects with opioid addiction, regardless of demographic and clinical presentations or treatment choice.

As pointed out above, the presence of specific patterns of psychological features or aggregates of psychiatric symptoms in people with addiction may be explained on the basis of the close neurobiological and neuropsychological links between addiction and other psychiatric conditions such as those pertaining to the mood, anxiety, or impulse control domains $[12,13,31,69,70]$. Clearly, some of the symptoms involved in the five identified dominant psychopathological groups may depend on the presence of a known comorbid psychiatric disorder or on the presence of a subthreshold mood, anxiety, and/or impulsive/dyscontrol spectrum manifestation. On the other hand, some symptoms may reflect the severity of opioid addiction, as well as the associated use or abuse of, or dependence on other drugs (cocaine, alcohol, or other stimulants and depressants), or a specific pattern of polyabuse. Currently, the longitudinal view of the psychopathology of addictive disorders should take into account a variety of components, such as pre-existing psychological/psychiatric conditions, substance effects/withdrawal symptoms, addictive processes (with psychiatric manifestations related to craving and dyscontrol), and including psychiatric consequences of the interaction between pre-existing conditions and addictive processes [13]. The interaction between all these psychiatric determinants helps to explain why the psychological/psychiatric presentations of people with addiction may diverge from the classical psychiatric nosography and be expressed, rather, through clinical pictures that may resemble, but not be exactly identifiable as, specifically known psychiatric disorders. Due to the deep interaction between different psychiatric determinants, it may be almost impossible to disentangle what pertains to addiction from what pertains to other independent psychopathological features. On these bases, even the 'dual diagnosis' construct itself has been questioned, and the need to deepen the investigation to identify the psychic structure of addiction is an issue that has been raised as an immediate concern [13].

When looking at the association between the five psychological/psychiatric dominant groups and the allocation to TC or OAT treatment-taking into account age, gender, heroin history length, previous treatments, working condition, and welfare benefits as potential confounders-'somatic symptoms' and 'violence-suicide' dominant dimensions are associated with OAT. This could be due to the fact that the somatic dimension, which may be closely correlated with the withdrawal condition, as well as violence and suicide features, may be better handled in an OAT, where the medical approach is stronger. Regarding the other confounding factors considered, it is plausible that patients with a short history of heroin and/or at their first treatment, as well as those who continue to work, may prefer a less demanding treatment such as OAT, which is likely to have a lower impact on their everyday life.

As regards the correlation between gender and psychopathological conditions as caught by SCL-90, while it does not seem to show any impact on patients requiring an OAT, it has an impact on patients undertaking TC: among these, males express a lower and females a higher level of psychopathology than patients entering an OAT. TCs appear to be more easily entered by females with more intense psychiatric symptoms. Differences in psychopathology between females and males with opioid addiction have been previously documented. Previous studies showed that females experience more serious psychological consequences from drug dependence, as well as a greater prevalence and severity of psychopathology than males [71-75]. This higher psychiatric severity is also associated with a higher level of dysfunction in the other areas of life (medical, drug-related, employment, and family/social) [71-73]. The preference of females for the TC treatment might be explained by the potential advantages offered by residential programmes in terms of the alleviation of psychiatric symptoms and the management of multiple needs. This is even more evident nowadays than in the past, since Italian TCs now offer a large variety of treatments, including methadone and buprenorphine treatment, as well as educational, psychological, psychiatric, and rehabilitative interventions.

\section{Limitations}

The psychological/psychiatric profiles of the subjects involved in both the samples were based on selfassessment through SCL-90, an instrument that is easy to administer, requiring few instructions and only a short time for completion. As the retrieved symptoms 
rely on subjective perceptions, they may differ from those perceived by an expert interviewer. It should be noted that since the patients were enrolled in many different care units, an apparently 'objective' evaluation would have not been possible: interviews would have been performed by different interviewers, so involving a high risk of interobserver differences. We therefore preferred a patientrelated self-assessment that allowed the investigation of symptoms in a dimensional perspective, while giving the opportunity to record the experience of the patient without the mediation of the examiner, rather than a non-uniform interviewer-related objective rating. On the other hand, it has to be acknowledged that this kind of patient may have a low level of insight, possibly causing his/her voluntary or involuntary hiding of some symptoms. As a result, caution is needed in interpreting these results, since they may be affected by the lack of any observerrelated 'objective' evaluation. The use of other instruments to check the tendency of patients to lie, their understanding of the questions that are put to them, and their motivation to participate in the procedure would certainly substantially improve the validity of our work.

Moreover, both samples of patients involved in our research are lacking in any formal psychiatric diagnosis. It must be pointed out that in Italy, psychiatric diagnosis is often formulated late in the course of the treatment received in addiction facilities or local addiction treatment units. In this connection, we have to point out that our research moves from the weakness of categorical psychiatric nosography and from the tendency to attribute symptoms expressed by addicted patients to pre-established psychiatric categories, such as forms of comorbidity. SCL-90 does not allow discrimination in terms of the impact of psychiatric problems: it is likely that a formal and objective psychiatric diagnosis would have made it possible to distinguish between people who do and do not have significant psychiatric conditions and to investigate the relationship between SCL-90-based psychopathological membership and psychiatric diagnosis. As a result, we are not yet in a position to know whether or how strongly the identified profiles are correlated with specific psychiatric diagnostic criteria.

A further limitation is that the SCL-90 questionnaire was administered only at entry into treatment, so results can only be considered representative of subjects with heroin addiction at that particular moment. Some symptoms may vary at different stages of the disease, whereas some may favour or limit certain treatment choices, so that they may prove to be under- or overweighted in our sample.

Moreover, the lack of information on other potential confounders of the association of opioid addiction with the five identified psychological/psychiatric dimensions should be taken into account: we cannot exclude the possibility that the identified profiles were influenced by the presence of opioid withdrawal, by the abuse of, or dependence on, other drugs, or by additional psychiatric disorders. In addition, we do not know whether these five dimensions are stable or whether they may change during the course of addiction.

Furthermore, the OAT sample and the TC cohort show differences in several factors (especially age and length of addiction). In particular, although we adjusted analyses for known confounding factors, the diagnostic procedures followed in the two samples of patients were clearly different: they were DSM-based for patients entering OAT and clinically based for those entering a TC. This may involve a misclassification bias. In this connection, it is important to make the point that given the implications involved in the choice of a residential programme-particularly in terms of limitations on the personal freedom of patients, that often result in dropouts, and higher costs for Italian public services-clinicians are usually required to use a careful approach to the diagnosis of dependence, which may entail the selection of patients who have a severe condition. In any case, the opposite possibility-of the inclusion in the TC sample of patients who did not reflect the full DSM diagnostic criteria-cannot be excluded, either. Therefore, a possible under- or overestimation of the true magnitude of the measures of association used in our study should be taken into consideration.

\section{Conclusions}

By looking at the entire group of answers given by patients with opioid addiction to the SCL-90 questionnaire at their entry into TC treatment, we obtained the same five psychopathological dimensions previously seen in subjects with opioid addiction entering an OAT. While these dimensions may be the expression of the links existing at the aetiological and physiopathological levels between addiction and other mental disorders, at this stage of the investigation, it is too early to draw any firm conclusion on the specific nature or the psychological/psychiatric determinants of the five identified dimensions. Further research is needed to confirm our results, to clarify the differences between the five psychopathological subgroups and their determinants, and to predict symptoms that can benefit from anticraving treatment or that need to be targeted separately.

\section{Competing interests}

The authors declare that they have no competing interests. IM served as Board Member for Reckitt Benckiser Pharmaceuticals, Mundipharma, D\&A Pharma, and Lundbeck. The sponsors had no role in the study design; in the collection, analysis, and interpretation of data; in writing the manuscript; or in the decision to submit the manuscript for publication.

\section{Authors' contributions}

PPP coordinated the VOECT study. ET, FVT, FM, RD, JG, AC, and AS coordinated the data collection. FM performed the data management of VOECT dataset. PPP, ET, AGIM and IM drafted the strategy of analysis and the 
present manuscript. PPP and ET reviewed the literature. IM made statistical analyses. FVT, FM, RD, AS, UK, LA, JG, AC, MD, and FF critically revised the article. All authors read and approved the final manuscript.

\section{Acknowledgements}

We thank Anthony Johnson for the language revision. We especially thank the patients and the staff of Italian TCs who made possible the implementation of the VOECT study.

\section{Funding}

The VOECT study was carried out within a study funded by the Italian Ministry of Health (Ricerca Finalizzata del Ministero della Salute, anno 2006). Additional funding was provided by the Region of Piedmont. No other financial support was requested for the study other than internal funds. Molteni Pharmaceuticals provided funds for open access publication.

\section{Author details}

${ }^{1}$ Social and Health Services, Cagliari Health Public Trust (ASL Cagliari), Cagliari, Italy. ${ }^{2}$ Department of Psychiatry, Cagliari Health Public Trust (ASL Cagliari), Cagliari, Italy. ${ }^{3}$ Piedmont Centre for Drug Addiction Epidemiology, ASLTO3 Grugliasco, Turin, Italy. ${ }^{4}$ Department of Clinical and Biological Sciences, University of Turin, Turin, Italy. ${ }^{5}$ Department of Epidemiology, Lazio Regional Health Service, Rome, Italy. ${ }^{6}$ National Coordination Hospitality Communities (CNCA), Rome, Italy. ${ }^{7}$ Regional Epidemiologic Observatory, Emilia Romagna Regional Health Service, Bologna, Italy. ${ }^{8}$ Department of Translational Medicine, Avogadro University, Novara, Italy. ${ }^{9}$ Department of Neurosciences, Vincent P. Dole Dual Diagnosis Unit, Santa Chiara University Hospital, University of Pisa, Pisa, Italy. ${ }^{10}$ Association for the Application of Neuroscientific Knowledge to Social Aims (AU-CNS), Pietrasanta, Lucca, Italy.

${ }^{11} \mathrm{G}$. De Lisio Institute of Behavioural Sciences, Pisa, Italy.

Received: 9 March 2014 Accepted: 26 October 2014

Published online: 18 November 2014

\section{References}

1. A.P.A: Diagnostic and Statistical Manual of Mental Disorders: DSM-5. 5th edition. Washington, D.C: American Psychiatric Association; 2013.

2. Regier DA, Farmer ME, Rae DS, Locke BZ, Keith SJ, Judd LL, Goodwin FK: Comorbidity of mental disorders with alcohol and other drug abuse. JAMA 1990, 19(264):2511-2518.

3. Kessler RC, McGonagle KA, Zhao S, Nelson CB, Hughes M, Eshleman S, Wittchen $\mathrm{H}-\mathrm{U}$, Kendler KS: Lifetime and 12-month prevalence of DSM-IIIR psychiatric disorders in the United States: results from the National Comorbidity Survey. Arch Gen Psychiatry 1994, 51:8-19.

4. Grant BF, Stinson FS, Dawson DA, Chou SP, Dufour MC, Compton W Pickering RP, Kaplan K: Prevalence and co-occurrence of substance use disorders and independent mood and anxiety disorders: results from the National Epidemiologic Survey on Alcohol and Related Conditions. Arch Gen Psychiatry 2004, 61:807-816.

5. Verheul R, Kranzler HR, Poling J, Tennen H, Ball S, Rounsaville BJ: Axis I and Axis II disorders in alcoholics and drug addicts: fact or artifact? J Stud Alcohol 2000, 61:101-110.

6. Volkow ND, Fowler JS, Wang GJ: Role of dopamine in drug reinforcement and addiction in humans: results from imaging studies. Behav Pharmacol 2002, 13:355-366.

7. Goldstein RZ, Volkow ND: Drug addiction and its underlying neurobiological basis: neuroimaging evidence for the involvement of the frontal cortex. Am J Psychiatry 2002, 159:1642-1652.

8. Brook DW, Brook JS, Zhang C, Cohen P, Whiteman M: Drug use and the risk of major depressive disorder, alcohol dependence, and substance use disorders. Arch Gen Psychiatry 2002, 59:1039-1044.

9. Volkow ND, Fowler JS, Wang GJ, Swanson JM: Dopamine in drug abuse and addiction: results from imaging studies and treatment implications. Mol Psychiatry 2004, 9:557-569.

10. Brady KT, Sinha R: Co-occurring mental and substance use disorders: the neurobiological effects of chronic stress. Am J Psychiatry 2005, 162:1483-1493.

11. Cuthbert BN: The RDoC framework: facilitating transition from ICD/DSM to dimensional approaches that integrate neuroscience and psychopathology. World Psychiatry 2014, 13:28-35.
12. Maremmani I, Perugi G, Pacini M, Akiskal HS: Toward a unitary perspective on the bipolar spectrum and substance abuse: opiate addiction as a paradigm. J Affect Disord 2006, 93:1-12.

13. Pani PP, Maremmani I, Trogu E, Gessa GL, Ruiz P, Akiskal HS: Delineating the psychic structure of substance abuse and addictions: should anxiety, mood and impulse-control dysregulation be included? J Affect Disord 2010, 122:185-197.

14. Ross HE, Swinson R, Doumani S, Larkin EJ: Diagnosing comorbidity in substance abusers: a comparison of the test-retest reliability of two interviews. Am J Drug Alcohol Abuse 1995, 21:167-185.

15. Kranzler HR, Kadden RM, Burleson JA, Babor TF, Apter A, Rounsaville BJ: Validity of psychiatric diagnoses in patients with substance use disorders: is the interview more important than the interviewer? Compr Psychiatry 1995, 36:278-288.

16. Hasin DS, Trautman KD, Miele GM, Samet S, Smith M, Endicott J: Psychiatric Research Interview for Substance and Mental Disorders (PRISM): reliability for substance abusers. Am J Psychiatry 1996, 153:1195-1201.

17. Samet S, Nunes EV, Hasin DS: Diagnosing comorbidity: concepts, criteria, and methods. Acta Neuropsychiatr 2004, 16:9-18.

18. Hasin D, Samet S, Nunes E, Meydan J, Matseoane K, Waxman R: Diagnosis of comorbid psychiatric disorders in substance users assessed with the Psychiatric Research Interview for Substance and Mental Disorders for DSM-IV. Am J Psychiatry 2006, 163:689-696.

19. Carpenter KM, Hittner JB: Dimensional characteristics of the SCL-90-R: evaluation of gender differences in dually diagnosed inpatients. J Clin Psychol 1995, 51:383-390.

20. Zack M, Toneatto T, Streiner DL: The SCL-90 factor structure in comorbid substance abusers. J Subst Abuse 1998, 10:85-101.

21. Maremmani I, Pacini M, Pani PP, Perugi G, Deltito J, Akiskal H: The mental status of 1090 heroin addicts at entry into treatment: should depression be considered a 'dual diagnosis'? Ann Gen Psychiatry 2007, 6:31.

22. Maremmani I, Pani PP, Pacini M, Bizzarri JV, Trogu E, Maremmani AGI, Perugi G, Gerra G, Dell'Osso L: Subtyping patients with heroin addiction at treatment entry: factors derived from the SCL-90. Ann Gen Psychiatry 2010, 9:15

23. Mathis F, Vigna-Taglianti F, Decidue R, Kirchmayer U, Piras G, Amato L, Ghibaudi J Camposeragna A, Saponaro A, Faggiano F, Trogu E, Pani PP: Studio "Valutazione dell'Offerta e dell'Esito dei trattamenti in Comunità Terapeutiche (VOECT), Ministero della Salute, Ricerca finalizzata. Monografia n. 1, Analisi descrittiva della coorte arruolata. Cagliari: Centro Stampa Regione Sardegna; 2013.

24. Derogatis LR, Lipman RS, Rickels K: The Hopkins Symptom Checklist (HSCL): a self report symptom inventory. Behav Sci 1974, 19:1-16.

25. Landis JR, Koch GG: The measurement of observer agreement for categorical data. Biometrics 1977, 33:159-174.

26. Blum K, Braverman ER, Holder JM, Lubar JF, Monastra VJ, Miller D, Lubar JO, Chen TJ, Comings DE: Reward deficiency syndrome: a biogenetic model for the diagnosis and treatment of impulsive, addictive, and compulsive behaviors. J Psychoactive Drugs 2000, 32:1-112.

27. Schuckit MA, Tipp JE, Bucholz KK, Nurnberger Jl, Hesselbrock Crowe RR, Kramer $\mathrm{J}$ : The life-time rates of three major mood disorders and four major anxiety disorders in alcoholics and controls. Addiction 1997, 92:1289-1304.

28. Gerra G, Angioni L, Zaimovic A, Moi G, Bussandri M, Bertacca S, Santoro G, Gardini S, Caccavari R, Nicoli MA: Substance use among high-school students: relationships with temperament, personality traits, and parental care perception. Subst Use Misuse 2004, 39:345-367.

29. Camacho A, Akiskal HS: Proposal for a bipolar-stimulant spectrum: temperament, diagnostic validation and therapeutic outcomes with mood stabilizers. J Affect Disord 2005, 85:217-230.

30. Conner KR, Sörensen S, Leonard KE: Initial depression and subsequent drinking during alcoholism treatment. J Stud Alcohol 2005, 66:401-406.

31. Volman SF, Lammel S, Margolis EB, Kim Y, Richard JM, Roitman MF, Lobo MK: New insights into the specificity and plasticity of reward and aversion encoding in the mesolimbic system. J Neurosci 2013, 33:17569-17576.

32. Post RM, Kalivas P: Bipolar disorder and substance misuse: pathological and therapeutic implications of their comorbidity and cross-sensitisation. Br J Psychiatry 2013, 202:172-176.

33. Shippenberg TS, Zapata A, Chefer VI: Dynorphin and the pathophysiology of drug addiction. Pharmacol Ther 2007, 116:306-321.

34. Heilig M, Egli M, Crabbe JC, Becker HC: Acute withdrawal, protracted abstinence and negative affect in alcoholism: are they linked? Addict Biol 2010, 15:169-184. 
35. Logrip ML, Koob GF, Zorrilla EP: Role of corticotropin-releasing factor in drug addiction: potential for pharmacological intervention. CNS Drugs 2011, 25:271-287

36. Maremmani I, Pacini M, Pani PP, Popovic D, Romano A, Maremmani AG, Deltito J, Perugi G: Use of street methadone in Italian heroin addicts presenting for opioid agonist treatment. J Addict Dis 2009, 28:382-388.

37. Maremmani AGl, Rovai L, Pani PP, Pacini M, Lamanna F, Rugani F, Schiavi E, Dell'Osso L, Maremmani I: Do methadone and buprenorphine have the same impact on psychopathological symptoms of heroin addicts? Ann Gen Psychiatry 2011, 10:17.

38. Deglon JJ, Wark E: Methadone: a fast and powerful anti-anxiety, anti-depressant and anti-psychotic treatment. Heroin Addict Relat Clin Probl 2008, 10:49-56

39. Pacini M, Maremmani I: Methadone reduces the need for antipsychotic and antimanic agents in heroin addicts hospitalized for manic and/or acute psychotic episodes. Heroin Addict Relat Clin Probl 2005, 7:43-48.

40. Schmauss C, Yassouridis A, Emrich HM: Antipsychotic effect of buprenorphine in schizophrenia. Am J Psychiatry 1987, 144:1340-1342.

41. Clouet DH: A biochemical and neurophysiological comparison of opioids and antipsychotics. Ann NY Acad Sci 1982, 398:130-139.

42. Gold MS, Donabedian RK, Dillard MJ, Slobetz FW, Riordan CE, Kleber HD: Antipsychotic effect of opiate agonists. Lancet 1977, 20:398-399.

43. Levinson I, Galynker II, Rosenthal RN: Methadone withdrawal psychosis. J Clin Psychiatry 1995, 56:73-76.

44. Yui K, Goto K, Ikemoto S, Ishiguro T, Angrist B, Duncan GE, Sheitman BB, Lieberman JA, Bracha SH, Ali SF: Neurobiological basis of relapse prediction in stimulant-induced psychosis and schizophrenia: the role of sensitization. Mol Psychiatry 1999, 4:512-523.

45. Boileau I, Dagher A, Leyton M, Gunn RN, Baker GB, Diksic M, Benkelfat C. Modeling sensitization to stimulants in humans: an [11C]raclopride/ positron emission tomography study in healthy men. Arch Gen Psychiatry 2006, 63:1386-1395.

46. Kalayasiri R, Kranzler HR, Weiss R, Brady K, Gueorguieva R, Panhuysen C, Yang BZ, Farrer L, Gelernter J, Malison RT: Risk factors for cocaine-induced paranoia in cocaine-dependent sibling pairs. Drug Alcohol Depend 2006, 84:77-84.

47. Thomas H: A community survey of adverse effects of cannabis use. Drug Alcohol Depend 1996, 42:201-207.

48. Chaudry HR, Moss HB, Bashir A, Suliman T: Cannabis psychosis following bhang ingestion. Br J Addict 1991, 86:1075-1081.

49. Solomons K, Neppe VM, Kuyl JM: Toxic cannabis psychosis is a valid entity. S Afr Med J 1990, 78:476-481.

50. Wylie AS, Scott RTA, Burnett SJ: Psychosis due to 'skunk'. BMJ 1995 311:125.

51. Hall W, Degenhardt L, Teesson M: Cannabis use and psychotic disorders: an update. Drug Alcohol Rev 2004, 23:433-443.

52. Burns JK: Pathways from cannabis to psychosis: a review of the evidence. Front Psychiatry 2013, 4:128

53. Bacciardi S, Maremmani AGl, Rovai L, Rugani F, Pani PP, Pacini M, Dell'Osso L, Akiskal HS, Maremmani I: Drug (heroin) addiction, bipolar spectrum and impulse control disorders. Heroin Addict Relat Clin Probl 2013, 15:29-36.

54. Kathleen Holmes M, Bearden CE, Barguil M, Fonseca M, Serap Monkul E, Nery FG, Soares JC, Mintz J, Glahn DC: Conceptualizing impulsivity and risk taking in bipolar disorder: importance of history of alcohol abuse. Bipolar Disord 2009, 11:33-40.

55. Maremmani I, Pacini M, Perugi G: Addictive disorders, bipolar spectrum and the impulsive link: the psychopathology of a self-regenerating pathway. Heroin Addict Relat Clin Probl 2005, 7:33-46.

56. Madden GJ, Petry NM, Badger GJ, Bickel WK: Impulsive and self-control choices in opioid-dependent patients and non-drug-using control participants: drug and monetary rewards. Exp Clin Psychopharmacol 1997 5:256-262.

57. Petry NM: Discounting of money, health, and freedom in substance abusers and controls. Drug Alcohol Depend 2003, 71:133-141.

58. Nigg JT, Wong MM, Martel MM, Jester JM, Puttler LI, Glass JM, Adams KM, Fitzgerald HE, Zucker RA: Poor response inhibition as a predictor of problem drinking and illicit drug use in adolescents at risk for alcoholism and other substance use disorders. J Am Acad Child Adolesc Psychiatry 2006, 45:468-475

59. Kirisci L, Tarter RE, Reynolds M, Vanyukov M: Individual differences in childhood neurobehavior disinhibition predict decision to desist substance use during adolescence and substance use disorder in young adulthood: a prospective study. Addict Behav 2006, 31:686-696.

60. Baldacchino A, Balfour DJ, Passetti F, Humphris G, Matthews K Neuropsychological consequences of chronic opioid use: a quantitative review and meta-analysis. Neurosci Biobehav Rev 2012, 36:2056-2068.

61. Nielsen DA, Kreek MJ: Common and specific liability to addiction: approaches to association studies of opioid addiction. Drug Alcohol Depend 2012, 123(Suppl 1):S33-S41.

62. Faggiano F, Vigna-Taglianti F, Versino E, Lemma P: Methadone maintenance at different dosages for opioid dependence. Cochrane Database Syst Rev 2003, 3:CD002208.

63. Mattick RP, Kimber J, Breen C, Davoli M: Buprenorphine maintenance versus placebo or methadone maintenance for opioid dependence. Cochrane Database Syst Rev 2008, 2:CD002207.

64. WHO: Guidelines for the Psychosocially Assisted Pharmacological Treatment of Opioid Dependence, www.who.int/substance_abuse/publications/ opioid_dependence_guidelines.pdf. Geneva: WHO; 2009. Accessed on September 21, 2014

65. Broekaert E, Vandevelde S, Soyez V, Yates R, Slater A: The third generation of therapeutic communities: the early development of the TC for addictions in Europe. Eur Addict Res 2006, 12:1-11.

66. Melnick G, De Leon G, Hiller ML, Knight K: Therapeutic communities: diversity in treatment elements. Subst Use Misuse 2000, 35:1819-1847.

67. Dye MH, Ducharme LJ, Johnson JA, Knudsen HK, Roman PM: Modified therapeutic communities and adherence to traditional elements. J Psychoactive Drugs 2009, 41:275-283.

68. Vanderplasschen W, Colpaert K, Autrique M, Rapp RC, Pearce S, Broekaert E, Vandevelde S: Therapeutic communities for addictions: a review of their effectiveness from a recovery-oriented perspective. Scientific World Journal 2013, 2013:427817.

69. Murphy A, Taylor E, Elliott R: The detrimental effects of emotional process dysregulation on decision-making in substance dependence. Front Integr Neurosci 2012, 6:101.

70. Bari A, Robbins TW: Inhibition and impulsivity: behavioral and neural basis of response control. Prog Neurobiol 2013, 108:44-79.

71. Kosten TR, Rounsaville BJ, Kleber HD: Ethnic and gender differences among opiate addicts. Int J Addict 1985, 20:1143-1162.

72. Green TC, Grimes Serrano JM, Licari A, Budman SH, Butler SF: Women who abuse prescription opioids: findings from the Addiction Severity Index-Multimedia Version Connect prescription opioid database. Drug Alcohol Depend 2009, 103:65-73.

73. Ross J, Teesson M, Darke S, Lynskey M, Ali R, Ritter A, Cooke R: The characteristics of heroin users entering treatment: findings from the Australian treatment outcome study (ATOS). Drug Alcohol Rev 2005, 24:411-418

74. Teesson M, Havard A, Fairbairn S, Ross J, Lynskey M, Darke S: Depression among entrants to treatment for heroin dependence in the Australian Treatment Outcome Study (ATOS): prevalence, correlates and treatment seeking. Drug Alcohol Depend 2005, 78:309-315.

75. Back SE, Payne RL, Wahlquist AH, Carter RE, Stroud Z, Haynes L, Hillhouse M, Brady KT, Ling W: Comparative profiles of men and women with opioid dependence: results from a national multisite effectiveness trial. Am J Drug Alcohol Abuse 2011, 37:313-323.

doi:10.1186/s12991-014-0035-x

Cite this article as: Pani et al:: Psychopathological symptoms of patients with heroin addiction entering opioid agonist or therapeutic community treatment. Annals of General Psychiatry 2014 13:35. 